\title{
M2M Call Termination - regulation or competition?
}

\author{
Tommy Staahl Gabrielsen* and Steinar Vagstad** \\ *Norwegian Competition Authority, **University of Bergen
}

June 12, 2008

\begin{abstract}
We review the recent literature on mobile termination rates (MTR) in mobile communication networks (M2M). This literature shows that mobile networks may have incentives to charge inefficient high termination charges leading to reduced surplus for consumers and society, and therefore should be regulated. We discuss optimal regulation of MTRs and the two main objectives behind current regulation: excessive pricing and entry assistance. We also present a sketch of a new regulatory regime for the mobile industry.
\end{abstract}

\section{$1 \quad$ Introduction $^{1}$}

Recent market liberalization in Europe aims at promoting efficiency through competition. An important industry in this respect is telecommunication. Deregulation and technological advances have changed this industry dramatically over the last few decades. From being an industry dominated by state-owned monopolies offering fixed-line services, today most countries have competing telecom service providers, with mobile services emerging as their most important product group. Today there are more mobile than fixed telephone subscribers on earth. According to Eurostat there were more than 364 million mobile phone subscriptions in the EU25 in 2003. This means that there were on average 80 subscriptions to mobile phones per 100 inhabitants compared to only 5 per 100 in 1995.

\footnotetext{
${ }^{1}$ The views expressed here are our own, and not necessarily those of the Norwegian Competition Authority or the University of Bergen. Note also that this work is preliminary and incomplete and should not be quoted.
} 
Reflecting the increased importance of mobile telephony, the industry has caught the interest of EU policy makers, and in 2002 a series of five new EU communication directives were designed to improve its performance. These directives require national regulatory authorities to carry out reviews of competition in communications markets to ensure that regulation remains appropriate in the light of changing market conditions. ${ }^{2}$

A key element of competitive telecom markets is the possibility of communication across networks. The technical part of the issue has largely been solved, so practically any two mobile phone subscribers anywhere in the world can call each other. The economic integration between networks is more of a worry for regulatory authorities. Typically, mobile telecom companies have mobile-to-mobile (M2M) call termination charges $^{3}$ that are higher than any reasonable cost estimate. ${ }^{4}$ High termination charges lead networks to engage in termination-based price discrimination: they charge higher prices for off-net calls than for on-net calls; a practice that has received considerable attention from regulators.

This purpose of this article is to review some of the recent contributions to the literature on call termination in M2M-network and to discuss the implications for the optimal regulation for this industry. The move from monopoly to competition offers great challenges to regulators. To regulate optimally regulators need to understand how competition works and with competition the complexity has increased. This is mainly due to the fact that whereas there is basically only one monopoly model there exist a wide range of competition models, and regulators should be able to discriminate between these. Secondly, regulators typically regulate prices based on some measures of costs. In mobile telephony there are high fixed costs and regulators need to decide on how these costs should be divided between different activities. Finally, as mentioned above, in order to make the physical interconnection between networks possible, the operators need to cooperate closely, and it might be a challenge to limit the cooperation to purely technical issues.

The remainder of this article is organized as follows. In the next section we will briefly discuss some central empirical features that we regard as important. Next, we review part of the recent literature on regulation

\footnotetext{
${ }^{2}$ Directives $\quad(2002 / 19 /$ EC $), \quad(2002 / 20 /$ EC $), \quad(2002 / 21 /$ EC $), \quad(2002 / 22 /$ EC $)$ (2002/77/EC).

${ }^{3} \mathrm{~A}$ termination charge or a termination fee is the amount a network charges to terminate a call that is originated outside its network.

${ }^{4} \mathrm{~A}$ prominent example is the British mobile communcations market. Ofcom (2003) argues that four of the largest operators in the UK (Vodaphone, Orange, O2 and TMobile) have charged termination charges "which appear to have been substantially above a reasonable estimate of each MNO's costs for a number of years,..".
} 
of termination charges. It should be noted that this review is not meant to be completely exhaustive. We focus on the contributions that we regard as most relevant for the policy debate. Finally, we discuss the implications for policy and conclude.

\section{Features of the mobile telecommunication industry}

Whichever industry is under scrutiny, it is often claimed that this particular industry is special and requires special attention or measures. We think that this claim is more true for the mobile telecommunications industry than for most others, and we will now proceed to describe three features of the industry that together make it a special one and, we think, call for special attention and measures.

First, the cost structure is somewhat special in that there are almost only fixed costs. ${ }^{5}$ By this we mean that the costs of serving a mobile phone subscriber are - by and large - the same whether or not the customer is using his or her phone. ${ }^{6}$ There are certainly costs associated with expanding business, like customer acquisition costs and investments to increase capacity. However, these are typically costs of connecting a particular consumer to one's network, and these costs are largely independent on his actual (marginal) use of his phone. This cost structure implies that marginal cost pricing is unattainable (and even unwanted) - firms must engage in some degree of markup pricing in order to break even. Exactly how the fixed costs should be allocated, however, remains a somewhat unsettled issue. A reasonable allocation method could lead to efficient utilizations of existing facilities and, at the same time, provide economic signals for guiding future capacity investments. $^{7}$

\footnotetext{
${ }^{5}$ Clearly, this holds also for other industries, like TV broadcasting, CATV, fixed-line telephony, and software development, to mention a few. Note the similarities between such a cost structure and the non-rivalry property of the textbook public goods.

${ }^{6}$ As an indication that the mobile phone networks are aware of this cost structure, high-demand customers are often offered contracts with a large number of free minutes. See e.g vodaphone.uk.

${ }^{7}$ Of course, similar problems arise other industries. Electricity transmission is a case in point. In Jing et al (2003) a comprehensive literature survey is made on available methods of electricity transmission fixed cost allocations. The review is conducted from several different aspects including: costs to be allocated, entities to pay the costs, system states to be based on, cost allocations of unused capacities, pricing of counter flow and that of reactive power, and allocation principles and methods. In addition, the characteristics of each method are analyzed and compared with those of the others.
} 
Second, the demand structure is special. Most consumption take place between pairs of consumers in a network, with limited possibilities for arbitrage. This facilitates the use of non-linear pricing schemes and price discrimination. Moreover, since both parties of a particular conversation may receive utility from the conversation, it is not clear who should be charged for the call. Different markets have adopted different pricing policies in this area. In Europe, typically only the calling party pays (dubbed CPP), while the US is an example of a country in which both parties typically pay. (This pricing policy or principle is often referred to as Receiving Party Pays or just RPP). This difference in pricing regime has significant bearings on both competition and regulation. Moreover, it can also be argued that the difference in pricing regimes in different countries can be traced back to differences in regulation policy — regulation of termination charges in particular — in the first place.

Third, mobile communication is a good example of a network industry: the value of subscribing to one mobile phone company's services depends on how easy it is (both technically and economically) to reach (and be reached by) other mobile phone subscribers. Earlier this was believed to imply that the efficient market structure was (possibly regulated) monopoly. The more modern view is that competition could and should be encouraged, but that careful action has to be taken in order to resolve the competition issues generated by the inherent strong network externalities. In particular, the different network companies should be forced to open up their networks to their competitors, facilitating seamless communication across different networks. This is the essence of the notion of interconnect. A paradox is worth noting here: well-functioning competition relies on the ability of the involved network companies to perfectly cooperate on lots of technical issued related to interconnect, and the same companies' inability to cooperate on competition issues.

Before we expand on the effects of different termination charges we will take a closer look at the actual pricing policies that are being pursued by typical mobile phone companies. As mentioned above, demand is structured in a way that make quite complex pricing schemes possible. A quick look at almost any mobile phone company's pricing policies reveals that the possibilities for complex pricing have been exploited to a substantial degree. The above-mentioned non-linearities are not confined to one or two two-part tariffs - consumers are typically offered the choice from extensive menues including several two-part tariffs and even more different block tariffs. This is in stark contrast to the relatively limited choice of pricing plans offered subscribers to services like fixed-line telephony or utilities like water or electricity, where the technology also facilitates complex pricing. Moreover, most pricing plans involve some sort of price discrimination, both in 
time (with evenings and weekends services being cheaper than business-hours services) and, more iterestingly, across termination "addresses". The most common price discrimination involves on-net services beeing cheaper than off-net services. But also subgroups of on-net services are often favored: "Friends\&Family" plans typically involves cheap (often free) calls to a limited, pre-chosen, set of phone numbers. Other frequently used schemes involves cheap (or free) calls to other customers with the same pricing plan as your own.

\section{Effects of markup on termination}

We will now review parts of the recent literature on call termination in mobile telecommunication networks. As noted above the cost structure in the industry - with high fixed costs and low or zero marginal costs — implies that the competition cannot be too fierce if we want several suppliers to survive in the long run. Therefore, in order to say something sensible about the effects of markup on termination we must have an idea of the competitive mode in the market. As discussed above, there is largely only one monopoly model, there are a whole class of different models of imperfect competition ranging from switching cost and product differentiation models to capacity constrained players and tacit collusion models. The different models have very different properties and the effect of termination charges potentially will differ from model to model.

A first issue regarding termination charges is how they are determined. In principle charges could be negotiated bilaterally og multilaterally, but they could also be regulated. In both cases termination charges could end up being symmetric (reciprocal) or asymmetric. Recently, there has been much discussion about whether regulation should be symmetric or asymmetric (in the sense that small operators are allowed to charge higher termination fees than larger operators).

We also know that the set of available contracts the operators can offer consumers potentially plays an important role. Models in which operators use non-linear pricing schemes yield quite other results compated with models in which pricing is confined to stricly linear tariffs. Models in which it is possible for the suppliers to price discriminate between on- and off-net calls yield predictions that deviate from those of models in which pricing is bound to be uniform. Moreover, models in which only the calling party is charged for a given call (CPP) yield results that differ from those of models in which also the receiving party be charged (RPP), and it is not clear whether both parties should be charged. 
Highly relevant for the RPP/CPP discussion is how consumer utilty is structured, and especially to what extent consumers receive utility for incoming calls. In its essence this is an empirical question, but one could easily imagine that the utility from incoming calls depends on whether CPP or RPP is implemented. Related to this is also what kind of calling pattern consumers have, more specific whether calling patterns are balanced or not. This is related to the existence of calling clubs (i.e. groups of consumers that call each other more frequently than they call others) and to and to what extent discrimination between on- and off net calls is implemented that induce calling clubs to locate on the same operator, but also to the relative size of operators.

Finally there are issues related to whether operators are network owners (MNOs) or virtual operators (MVNOs) that rent capacity from the MNOs. Regulation of termination also should take into account the prospect of entry, and then both from MNOs and MVNOs. This raises possible conflicts between efficiency in the short and long run.

The literature on M2M termination that will be reviewed below differs along all these dimensions. There are many potential ways such a review could be organized. We have chosen to organise this review in the following way. First we explore the literature that assumes symmetriccaly sized incumbent MNOs without entry, and we investigate the incentives the firms have to charge high termination fees under different assumptions regarding consumer tariffs, the possibility of price discrimination and calling patterns. Thereafter we move to the literature assuming asymmetric networks and where also the prospects of entry is taken into account.

\subsection{Symmetric incumbent networks}

One part of the literature on M2M termination studies a situation with only symmetric and incumbent firms. From this strand of the literature we have chosen Laffont et al (1998a,b), Armstrong (1998), Gans and King (2001) and Gabrielsen and Vagstad (2008).

Assuming linear and uniform pricing, Armstrong (1998) and Laffont et al (1998a) have suggested that access charges are high because firms want high prices, and high access charges make them charge high prices. ${ }^{8}$ High access charges imply high perceived marginal costs and high prices, but the high costs are then compensated for by correspondingly high access revenues. Consequently, high access charges can be an instrument for obtaining high prices. However, Laffont, Rey and Tirole (1998b) demonstrate that if the

\footnotetext{
${ }^{8}$ For a survey of the theory of access pricing and interconnection, see Armstrong (2002).
} 
operators can discriminate between on-net and off-net traffic and have access to two-part tariffs, high access fees can no longer be used to facilitate high prices. On the contrary, high access charges tend to reduce equilibrium profits, as the access charge makes the firms distort consumer prices with an implied welfare loss, reducing the consumers' willingness to pay for subscription. Later, Gans and King (2001) have shown that in this context access prices should be lower than marginal costs of terminating a call. With a negative markup consumers will want to belong to the smaller network. This is due to the fact that then relatively more of the call will be cheaper off-net calls. This in turn means that firms will be less interested in gaining market shares and therefore competition is dampened and profits increased.

However, in many Telecom markets linear and uniform prices are the exception rather than the rule. It thus remains an open question whether symmetric incumbent networks will have incentives to sustain high access charges as an equilibrium outcome.

\subsubsection{Unbalanced calling patterns: Calling clubs}

Gabrielsen and Vagstad (2008) show that even symmetric incumbents may sustain high access charges. Their results are based on the interaction between three different features. The first is the tariff-mediated network externalities that arises when firms discriminate against off-net traffic: Subscribing to a large network lowers the average price of calls. Tariff-mediated network externalities are already present in Laffont et al (1998b) but are not sufficient to facilitate high prices on their own. ${ }^{9}$

The second feature is the existence of exogenous switching costs: consumers have a relationship with one of the suppliers, and there are certain costs attached to switching supplier. ${ }^{10}$ As shown by Klemperer $(1987,1995)$, such switching costs facilitate high prices, but with two-part tariffs and nonuniform pricing, switching costs do not call for inefficient pricing: Marginal prices (access charges inclusive) should equal marginal costs, and the market power that arises due to switching costs should be used to increase the fixed fee of the two-part tariff. Consequently, the existence of switching costs alone is no reason to set high access charges.

\footnotetext{
${ }^{9}$ In an attempt to restore the collusion effect from high access charges Dessein (2003) introduces heterogeneity in volume and subscription demand. However, neither of these features are sufficient to restore the result of high access charges in equilibrium. (Dessein does not allow networks to charge different prices for on-net and off-net calls.)

${ }^{10}$ One example of switching costs in the present setting is the costs of searching for and finding a better supplier, and then establishing a relationship with this new firm and terminating the relationship with the old firm.
} 
Third, despite the fact that mobile phone owners can reach more than a billion other persons, they place their calls to a limited number of people, among which friends, family and workmates comprise the bulk of the recipients. The notion of a calling club captures the phenomenon that individuals do not place their calls randomly across networks, but have a bias towards repeatedly calling other members of their calling club (their 'friends').

The combination of calling clubs and tariff-mediated network externalities works as follows: with higher off-net than on-net prices, members of the same calling club would benefit from joining the same network, all else equal. Once they have coordinated on the same network, each member of the calling club strictly prefers to stay with that network: Switching to another network will make it more expensive to reach one's friends in the old network and by that make it more expensive to make calls, even if both networks charge identical prices and have the same number of subscribers. Consequently, this type of consumer lock-in will reduce competition, albeit at a certain cost. As long as high access charges do not reflect real costs, price discrimination based on call termination is inefficient and will reduce total surplus compared to a situation in which firms set all marginal prices at their marginal costs.

Hence, high access charges basically have two effects. First it will distort call prices as firms will have incentives to increase off-net prices. This will reduce consumers' utility from subscription and reduce their willingness to pay subscription fees. The second effect is that discrimination based on call termination will increase individual switching costs because consumers will be more reluctant to relocate away from their calling club. This effect enables firms to increase the subscription fees, and Gabrielsen and Vagstad (2008) show that the latter effect may indeed dominate the former, hence making markups on termination profitable.

\subsection{The CPP/RPP-debate}

In a policy article Littlechild (2006) claims that the problems related to termination charges partly is due to the "calling party pays"- (CPP) principle, and that overcharging of termination is not a problem in countries with "receiving party pays" (RPP). He argues that price controls that are inherently linked to CPP are ineffective and that the adminstrative costs of the regulation system i CPP-countries are substantial. RPP-countries has to a large extent avoided the regulatory costs by imposing the obligation to terminate calls without charge. Instead operators may - insofar there are specific costs associated with termination - recover these costs by charging customers for incoming calls. This argument seems to rely on that there are real costs associated with termination. The fact that many operators price on-net calls 
at zero indicate that termination costs may be negligible.

The solution to CPP countries is - according to Littlechild - to impose bill and keep and let operators have the discretion on how to charge their own customers, i.e. whether to impose CPP or RPP.

\subsection{Asymmetric networks and entry}

Another strand of the literature analyzes the effects of mobile termination rates for asymmetric networks and entry (Calzada and Valetti (2008), Peitz (2005a,b) and Dewenter and Haucap (2005)). With asymmetric firms it is well regognized that network externalities are to the benefit of large operators and to the detriment of smaller ones, and that when incumbents are able to charge high termination charges, entry will be reduced.

Calzada and Valetti (2008) investigate a setup where there is a group of unregulated incumbent operators that can negotiate reciprocal access charges, initially unthreathened by entry. The operators first negotiate a markup on termination and then compete. Competition can either be in setting two-part tariffs with on- and off net discrimination to consumers, or in net utilities ${ }^{11}$. Finally consumers choose where to subscribe. When competition is in prices the socially efficient termination markup is zero. In the model however, operators will agree on an inefficient negative markup on call termination. This result is essentially the same as in Gans and King (2001), as discussed above.

When there is a potential entrant the incentives are dramatically changed. With potential entry the authors consider the case of non-discriminatory access charge, i.e. the incumbents cannot charge more for termination from the entrant they they do from each other. In this setting the incumbents face a trade-off. By charging low (negative) termination markups they maximize industry profits for a given number of firms, but run the risk of attracting too much entry. Basically, in this model entry will be deterred by agreeing on a high access charge when fixed costs of entry is high enough, and entry is accomodated for low enough entry cost. However, the welfare consequences of markup on access are unclear. This is due to the fact that in the model they use (standard logit model) entry may be excessive without markups, and therefore restrictions on entry may be socially preferable. However, consumers will always loose from termination markups in this model

Peitz $(2005 \mathrm{a}, \mathrm{b})$ consider the effects of asymmetric regulation of termination charges in two different setups. First, in Peitz 2005a, the case of uniform

\footnotetext{
${ }^{11}$ We only discuss the case here where competition is in prices. See Calzada and Valetti for more details when competion is in net utilities.
} 
pricing is considered, and then Peitz (2005b) considers the case of on- and off-net discrimination. With uniform pricing Peitz (2005a) shows that asymmetric regulation, i.e. cost based termination for a large incumbent and a markup for a smaller entrant, may be preferable (compared to the best symmetric regulation) both for consumers and for society as a whole. The basic idea is that an access markup for the entrant will make entry more attractive, and this will increase competition. The downside for the consumers is that the incumbent will respond to entry by increasing its marginal price, but the positive effect from increased competition will dominate this effect. Once the entrant has reached a $50 \%$ market share, asymmetric regulation is no longer needed. In fact, absent the possibility of further entry the market will regulate istself; no operator will have incentives to charge a markup on termination.

When operators can engage in termination based price discrimination similar results apply. The beneficial effect for consumers still apply, but in contrast to the previous model welfare now may be hurt by asymmetric termination fees. The driving force behind the negative effect on welfare is that the entrant's markup on termination induces the incumbent to increase its off-net price too much. The conclusion from Peitz $(2005 \mathrm{a}, \mathrm{b})$ is that asymmetric regulation turns out to be more problematic when termination based price discrimination is possible than under uniform pricing.

Finally, Dewenter and Haucap (2005) also consider regulation of termination of asymmetric networks. The basic feature of their model is that consumers are unaware of the exact price of calling a specific number, and therefore will place calls based on average prices. ${ }^{12}$ The consumers' ignorance will create a negative pricing externality as a price increase of one firm will not only affect that specific firm's demand negatively, but also the demand of its rivals. More specifically, this externality may induce networks to increase their termination charges to inefficient high levels which calls for regulation of termination charges. The authors show that the incentives to increase termination charges are higher for smaller operators than for larger ones. This is again due to the fact that smaller operators can increase their termination fees significantly without losing much demand while larger operators will suffer more from demand reduction if they increase termination charges. The authors hold the view that in general termination fees should be unregulated, although such a conclusion is very difficult to draw from the analysis presented. However, if one chooses to regulate larger firms the main policy conclusion from the analysis is that also small operators should be regulated.

\footnotetext{
${ }^{12}$ This story is also developed by Gans and King (2000) and Wright (2002).
} 


\section{Implications for regulation}

As we have seem above termination markups can serve as a device to reduce competition between incumbent and symmetric networks. For such a strategy to be profitable the existence of coordinated calling clubs and switching costs are needed, and price discrimination based on call termination must be possible. With asymmetries in size, networks with more subscribers will benefit more from markups on termination than smaller firms.

We have also seen that high termination charges may be used by incumbents as a device to deter or soften entry. Moreover, asymmetric regulation - meaning softer regulation of entrants - may induce more entry thus leading to more intense competition in the long run.

When asymmetric termination charges are imposed, the objective is often to ease the situation for the smaller or newer network, by shifting profit from a presumably competitive large incumbent to a presumably not-socompetitive smaller entrant. Asymmetric regulation has, in principle, four different effects on the operating networks' profits. First, networks who are allowed to charge higher termination fees (i.e. the smaller networks) will run a termination (or access) surplus while networks who are required to set a lower termination charge (i.e. the large incumbent(s)) will run a corresponding termination deficit. This is a direct profit-shifting effect of asymmetric termination charges. Second, the marginal costs of services will increase for larger networks relative to smaller networks. This will make the smaller networks more competitive in a more indirect way. Third, if all networks are allowed to charge termination fees (symmetric or asymmetric) that are higher than the true marginal costs (which we have argued are zero), this will tend to create tariff-mediated network externalities that favor larger networks over smaller ones. Fourth and finally, termination markup may reduce the competition between the networks, and this effect will increase profits of all active networks.

Present regulation in most M2M markets is of course a mix of these: networks are allowed to charge positive termination fees (which in itself favor large networks over small ones due to the network externalities that are created), small networks are allowed to charge higher fees than larger networks (which both directly and indirectly favor small networks over large ones), and the termination markup sometimes contribute to reduced competition (which favor all networks).

We subscribe to the idea that the regulator shoud pay particular attention to the situation of smaller networks. The question, however, is whether this can be achieved without the inefficiencies associated with termination markups. Consider a market with $N$ networks, each with $n_{i}$ subscribers. 
With a balanced call pattern the traffic in each direction between any two networks $i$ and $j$ is proportional with the product $n_{i} n_{j}$. (Actual traffic need of course not be balanced, either because of pricing differences between the two networks, because the two networks attract different types of consumers, or both.) This implies that with a balanced call pattern and reciprocal (i.e. symmetric) termination charges there are no financial reason for any two networks to charge each other for termination: network $i$ 's termination bill to network $j$ will be equal to network $j$ 's bill to network $i$.

Suppose that with the present asymmetric regulation, firm $i$ earns a profit of $\pi_{i}^{0} \geq 0$. Next, suppose that we instead implement a regulatory regime in which marginal termination charges are set to zero for all (pairs of) networks. If all $N$ networks remain active, the new regime will, without any further adjustments, yield net profit of $\pi_{i}^{1}$ (which may be positive or negative) for each firm $i$. As long as the total profit $\Sigma_{i} \pi_{i}^{1}$ is positive, the regulator can maintain all $N$ firms active by shifting profit between networks in a way that is not related to actual traffic. ${ }^{13}$ If, as seems natural, the asymmetry in profits is related to network size, the amount to be shifted from network $i$ to network $j$ this way, denoted $S_{i j}$, can in general terms be written

$$
S_{i j}=S\left(n_{i}, n_{j}\right),
$$

where the transfer function $S($,$) is set such that \pi_{i}^{1}-\sum_{j \neq i} S\left(n_{i}, n_{j}\right) \geq 0$ for each network $i$.

As we have discussed, the problem with a positive markup on termination is that this leads the networks to charge distorted (higher) prices on off-net calls, in turn leading to tariff-mediated network externalities. Our proposed regulation resolves this particular problem with regulation, without being informationally more demanding: even within the current regulatory regime with asymmetric marginal termination prices, a thorough analysis must be undertaken to figure out exactly how much higher the smaller networks' termination fees should be. For both regulatory regimes a sound model of how competition works is a natural starting point, and such a model is needed to estimate the profit expressions $\pi_{i}^{0}$ and $\pi_{i}^{1}$.

Moreover, in both regimes one has to make up one's mind about how many networks we want. There are large fixed costs and substantial economies of scale in this industry, and, as mentioned above, it might be the case that with our proposed regulation, the combined profit of all networks is negative. This is not necessarily bad news, as it implies that competition is too fierce with $N$ firms in the market, and therefore that we can do with fewer firms, with

\footnotetext{
${ }^{13}$ Note, however, that if the anti-competitive effect of termination markup is sufficiently strong, total profit need not be positive after the termination fees are forced to zero.
} 
less duplication of fixed costs as a result. If so, this would constitute yet another advantage of regulatory reform. ${ }^{14}$

Further research should focus on investigating our proposed scheme for different competition models. Moreover, careful attention should be paid to investigating the incentives such a regulatory scheme would give for arbitrage and rent-seeking. These and other issues are left to future research.

\section{References}

[1] Armstrong, M. (1998): Network Interconnection in Telecommunications. Economic Journal, 108: 545-564.

[2] Armstrong, M. (2002): The theory of Access Pricing and Interconnection. In M. Cave, S. Majumdar and I. Vogelsang (eds): Handbook of Telecommunications Economics. North Holland.

[3] Calzada J. and T. M. Valetti (2008): Network Competition and Entry Deterrence, Economic Journal, forthcoming.

[4] Dessein, W. (2003): Network Competition in Nonlinear Pricing. RAND Journal of Economics, 34, 593-611.

[5] Dewenter, R. and J. Haucap (2005): The effects of regulating mobile termination rates for asymmetric networks, European Journal of Law and Economics, 20: 185-197.

[6] Gabrielsen, T.S. and S. Vagstad (2008): Why is on-net traffic cheaper than off-net traffic? Access markup as a collusive device?, European Economic Review 52: 99-115.

[7] Gans, J. S. and S. P. King (2000): Mobile Network Competition, Customer Ignorance and Fixed-to-mobile Call Prices, Information Economics and Policy, 12: 301-327.

[8] Gans, J. S. and S. P. King (2001): Using 'bill and keep' Interconnect Arrangements to Soften Network Competition, Economics Letters, 71: 413-420.

\footnotetext{
${ }^{14} \mathrm{~A}$ note of caution is appropriate at this point: some imperfectness of competition is needed to "make room for" more than one network, and one might worry that banning termination markups will intensify competition so much that there will not be room for more than one network. While we suspect that today's termination markups reduce competition, we do not believe this effect is so strong that one should worry about it. However, this is an empirical question that has to be addressed.
} 
[9] Jing, Z.; X. Duan, F. Wen, Y. Ni and F.F. Wu (2003): Review of transmission fixed costs allocation methods. Power Engineering Society General Meeting, 2003, IEEE Volume 4, 13-17 July 2003, pp. 2585-2592.

[10] Klemperer, P. (1987): Markets with consumer switching costs, Quarterly Journal of Economics 102, 375-94.

[11] Klemperer, P. (1995): Competition when consumers have switching costs: An overview with applications to Industrial Organization, macroeconomics, and international trade, Review of Economic Studies 62, 515-39.

[12] Laffont, J.J., P. Rey and J. Tirole (1998a): Network Competition: I. Overview and Nondiscriminatory Pricing, RAND Journal of Economics, 29: $1-37$.

[13] Laffont, J.J., P. Rey and J. Tirole (1998b): Network Competition: II. Price Discrimination, RAND Journal of Economics, 29: 38-56.

[14] Littlechild, S. C. (2006: Mobile termination Charges: Calling Party Pays versus Receiving Party Pays, Telecommunications Policy, 30: 242-277.

[15] Ofcom (2003): Wholesale Mobile Voice Call Termination. Proposals for the identification and analysis of markets, determination of market power and setting of SMP conditions (www.ofcom.org.uk/consult/condocs/mobile_call_termination).

[16] Peitz, M. (2005a): Asymmetric access price regulation in telecommunications markets, European Economic Review, 49: 341-358.

[17] Peitz, M. (2005b): Asymmetric regulation of access price and price discrimination in telecommunications, Journal of Regulatory Economics, 28: $327-343$.

[18] Wright, J. (2002): Access Pricing Under Competition: An Application to Cellular Networks, Journal of Industrial Economics, 50: 289-315. 